tained on as few drugs as possible if only to reduce the traffic across the oesophageal mucosa.

\author{
References \\ ${ }^{1}$ Mason, D. I. R., et al., Health Bulletin, 1975, 33, 72. \\ 2 Ritchie, D. M., et al., Quarterly fournal of Medicine, 1968, 37, 383. \\ ${ }^{3}$ Lee, P., et al., Scandinavian fournal of Rheumatology, 1974, 3, 17. \\ ${ }^{4}$ Hucker, H. B., et al., Fournal of Pharmacology and Experimental Thera- \\ peutics, 1966, 153, 237. \\ 5 Emori, H. W., et al., Annals of the Rheumatic Diseases, 1973, 32, 433. \\ ${ }^{6}$ O'Brien, W. M., Clinical Pharmacology and Therapeutics, 1968, 9, 94. \\ ${ }^{7}$ Deodhar, S. D., et al., Quarterly fournal of Medicine, 1973, 42, 387. \\ ${ }^{8}$ Co-operating Clinics of the American Rheumatism Association, Clinical \\ Pharmacology and Therapeutics, 1967, 8, 11. \\ ${ }^{9}$ Jeremy, R., and Towson, J., Medical Fournal of Australia, 1970, 2, 127.
}

10 Yesair, D. W., et al., Biochemical Pharmacology, 1970, 19, 1591.

11 Rubin, A., et al., Arthritis and Rheumatism, 1973, 16, 635.

12 Champion, G. D., et al., Clinical Pharmacology and Therapeutics, 1972, 13, 239.

${ }^{13}$ Lindquist, B., et al., Clinical Pharmacology and Therapeutics, 1974, 15, 247.

14 Mielens, Z. E., et al., fournal of Pharmacology, 1968, 20, 567.

15 Swingle, K. F., et al., fournal of Pharmacology and Experimental Therapeutics, 1970, 172, 423.

16 Pitkeathly, D. A., et al., Annals of the Rheumatic Diseases, 1966, 25, 334.

17 Pinals, R. S., and Frank, S., New England Fournal of Medicine, 1967, 276, 512.

${ }^{18}$ Lee, P., personal communication.

19 Melmon, K. L., New England fournal of Medicine, 1971, 284, 1361.

20 Lee, P., et al., Annals of the Rheumatic Diseases, 1973, 32, 565.

21 Brooks, P. M., et al., Health Bulletin, 1975, 33, 108.

22 Lee, P., et al., British Medical fournal, 1973, 2, 685.

${ }_{23}$ Van Arman, C. G., and Nuss, G. W., Pharmacologist, 1970, 12, 202.

\title{
Carbon Monoxide Yields of Cigarettes and Their Relation to Nicotine Yield and Type of Filter
}

\author{
M. A. H. RUSSELL, P. V. COLE, M. S. IDLE, L. ADAMS
}

British Medical fournal, 1975, 3, 71-73

\section{Summary}

Carbon monoxide (CO) yields of 11 popular brands of British cigarette, two types of cigarette containing tobacco-substitute, and one brand of cigar were measured under standardized conditions. Yields of the conventional cigarettes ranged from 5.0 to $20.2 \mathrm{mg}$ per cigarette (1.3 to $4.7 \%$ by volume). The cigar yielded $81.7 \mathrm{mg} \mathrm{(10.0} \%)$ CO and the two semi-synthetic cigarettes $17.2(4.2 \%)$ and $28.2 \mathrm{mg}(6.2 \%)$ CO. Puff-by-puff analysis showed an increase in $\mathbf{C O}$ concentration as a cigarette is smoked. In brands with nicotine yields over $1.0 \mathrm{mg}$ no relationship was apparent between nicotine yield and $\mathrm{CO}$ yield, and the filters of cigarettes in this category did not appear to reduce the $\mathrm{CO}$ yield. In the low nicotine cigarettes with ventilated filters there appeared to be some correlation between nicotine yield and $\mathrm{CO}$ yield, and these filters were highly effective in reducing $\mathrm{CO}$ yield, owing mainly to the ventilation. We suggest that official publication of $\mathrm{CO}$ yields might motivate manufacturers to produce cigarettes with lower yields.

\section{Introduction}

In April 1973 the Government published for the first time the tar and nicotine yields of cigarettes sold in the United Kingdom. ${ }^{12}$ The purpose of such a "league table" is presumably to serve as a guide to those who seek a less harmful cigarette. But is it enough to be guided only by tar and nicotine yields? What about carbon monoxide?

$\overline{\text { Addiction Research Unit, Institute of Psychiatry, Maudsley Hospital, }}$ London S.E.5

M. A. H. RUSSELL, M.R.C.P., M.R.C.PSYCH., Senior Lecturer and Honorary Consultant Psychiatrist

St. Bartholomew's Hospital, London E.C.1

P. V. COLE, M.B., F.F.A.R.C.S., Consultant Anaesthetist

M. S. IDLE, B.SC., Research Assistant

L. ADAMS, B.SC., Research Assistant
In the 1920s the carbon monoxide (CO) content of tobacco smoke was shown to vary with the brand of cigar or cigarette. ${ }^{3}$ 4 This was confirmed in America ${ }^{5}{ }^{6}$ but there are no published figures for $\mathrm{CO}$ yields of British cigarettes. We have shown that the increase in blood carboxyhaemoglobin ( $\mathrm{COHb}$ ) due to smoking varies considerably with the brand of cigarette, ${ }^{78}$ which provides indirect evidence that cigarettes may vary in their $\mathrm{CO}$ yield. We have now made direct measurements of the $\mathrm{CO}$ concentration in mainstream smoke of a range of cigarettes on sale in Britain.

\section{Materials and Methods}

Selected brands of cigarette were purchased in batches of 100. Each batch in turn was placed in a single horizontal layer inside a Perspex tank kept at $21^{\circ} \mathrm{C}$ and $60 \%$ relative humidity and left there for at least 48 hours. Each cigarette was then weighed and the pressure drop across it at a fixed flow rate $(19.2 \mathrm{ml} / \mathrm{s})$ estimated. Damaged ones were then discarded. From each batch the ones having a weight within 20 $\mathrm{mg}$ and a draw resistance within $4 \%$ of the respective means were selected. Usually 15 to 25 cigarettes were returned to the conditioning chamber until needed for analysis.

The cigarettes were smoked in standard fashion using a smoking machine of our own design. This consisted of an electrically operated linear actuator operating a gas-tight glass syringe. The syringe port was connected via a three-way plastic tap to a piece of soft latex tubing, which acted as a cigarette holder. The cigarette was fixed in position and carefully lit with an electric cigar lighter. Each puff was exactly $35 \mathrm{ml}$ and took $1.82 \pm S . D .0 .02 \mathrm{~s}$. The smoke was then expelled through two 8-nm Millipore filters in series (to remove particulate matter) and collected in a 1-litre plastic sampling bag. ${ }^{9}$ Smoking was continued in this way, with exactly one minute between puffs, until the burning end reached a mark a fixed distance from the unlit end. This distance was $20 \mathrm{~mm}$ or the tip overwrap plus 3 $\mathrm{mm}$, whichever was the greater. The number of puffs needed to reach the mark was noted. The technique employed was so far as possible in line with standard procedure. ${ }^{10}$

The contents of the sampling bag were analysed for $\mathrm{CO}$ with a non-dispersive infrared analyser (Hartmann and Braun, URAS 2). The total yield of each cigarette was then calculated and expressed in mg. Though the measurement of $\mathrm{CO}$ necessitated the removal of water vapour produced in smoking the amount produced was too small to affect significantly the measured concentrations. At the low sensitivity required for measurement of $\mathrm{CO}$ the analyser was found to be insensitive to the levels of carbon dioxide produced by burning cigarettes. 
Brands of Cigarettes Analysed together with their Mean Carbon Monoxide Yields ( \pm S.E. of Mean) and Other Data

\begin{tabular}{|c|c|c|c|c|c|c|c|}
\hline \multirow[b]{2}{*}{ Brand* } & \multirow{2}{*}{$\begin{array}{l}\text { Nicotine } \\
\text { Yield } \\
\text { (mg) }\end{array}$} & \multirow{2}{*}{$\begin{array}{c}\text { Tar } \\
\text { Yield } \\
\text { (mg) }\end{array}$} & \multirow{2}{*}{$\underset{\text { Weight }}{\text { Mean }}$} & \multirow{2}{*}{ 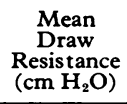 } & \multirow{2}{*}{$\begin{array}{c}\text { Mean } \\
\text { No. of } \\
\text { Puffs per } \\
\text { Cigaret te }\end{array}$} & \multicolumn{2}{|c|}{ Carbon Monoxide Yield } \\
\hline & & & & & & $\begin{array}{c}\text { Mean Concentration } \\
\text { (Vol. \%) }\end{array}$ & $\underset{\text { (mg/Cigarette) }}{\text { Mean Yield }}$ \\
\hline $\begin{array}{l}\text { (1) Silk Cut Extra Mild } \dagger \\
\text { (2) Player's Mild De Luxe } \dagger \\
\text { (3) Silk Cut } \dagger \\
\text { (4) Embassy Extra Mild } \dagger \\
\text { (5) Embassy Gold } \\
\text { (6) Player's No. 6 Filter } \\
\text { (7) Embassy Filter } \\
\text { (8) Senior Service Plain } \\
\text { (9) Player's Medium Navy Cut } \\
\text { (10) Gold Flake } \\
\text { (11) Capstan Full Strength } \\
\text { (12) X (tipped) } \\
\text { (13) Planet (tipped) } \ddagger \\
\text { (14) Manikin Cigar }\end{array}$ & $\begin{array}{c}0.14 \\
<0.3 \\
0.7 \\
0.8 \\
1.1 \\
1.2 \\
1.2 \\
1.4 \\
1.6 \\
2.0 \\
3.4 \\
1.0\end{array}$ & $\begin{array}{r}<4 \\
<4 \\
11 \\
11 \\
18 \\
18 \\
19 \\
23 \\
26 \\
32 \\
38 \\
18\end{array}$ & $\begin{array}{r}975 \\
917 \\
1000 \\
879 \\
763 \\
754 \\
989 \\
1049 \\
1087 \\
1080 \\
1094 \\
992 \\
1168 \\
1733\end{array}$ & $\begin{array}{r}20 \cdot 1 \\
24 \cdot 0 \\
15 \cdot 4 \\
12 \cdot 8 \\
16 \cdot 5 \\
15 \cdot 4 \\
12 \cdot 4 \\
9 \cdot 3 \\
9 \cdot 8 \\
9 \cdot 9 \\
9 \cdot 1 \\
12 \cdot 6 \\
15 \cdot 1 \\
5 \cdot 9\end{array}$ & $\begin{array}{r}8 \cdot 1 \\
6 \cdot 9 \\
7 \cdot 7 \\
8 \cdot 5 \\
7 \cdot 5 \\
7 \cdot 0 \\
9 \cdot 0 \\
9 \cdot 7 \\
7 \cdot 6 \\
9 \cdot 9 \\
8 \cdot 8 \\
8 \cdot 8 \\
9 \cdot 7 \\
17 \cdot 5\end{array}$ & $\begin{array}{r}1.3 \pm 0.06 \\
2 \cdot 0 \pm 0.10 \\
2.9 \pm 0.12 \\
3.0 \pm 0.09 \\
4 \cdot 2 \pm 0.14 \\
4.7 \pm 0.11 \\
4.6 \pm 0.08 \\
4 \cdot 4 \pm 0.06 \\
3.5 \pm 0.17 \\
4.3 \pm 0.05 \\
4.0 \pm 0.12 \\
4.2 \pm 0.08 \\
6.2 \pm 0.13 \\
10.0 \pm 0.25\end{array}$ & $\begin{array}{l}4.95 \pm 0.24 \\
6.43 \pm 0.31 \\
10.38 \pm 0.36 \\
12.11 \pm 0.46 \\
14.70 \pm 0.58 \\
15.31 \pm 0.37 \\
19.22 \pm 0.34 \\
20.22 \pm 0.38 \\
12.50 \pm 0.60 \\
20.02 \pm 0.25 \\
16.68 \pm 0.64 \\
17.20 \pm 0.42 \\
28.16 \pm 0.67 \\
81.71 \pm 2.1\end{array}$ \\
\hline
\end{tabular}

*Brands (1) to (7) have filter tips; (8) to (11) are plain.

These cigarettes have ventilated filters.

†These brands contain synthetic tobacco-substitute.

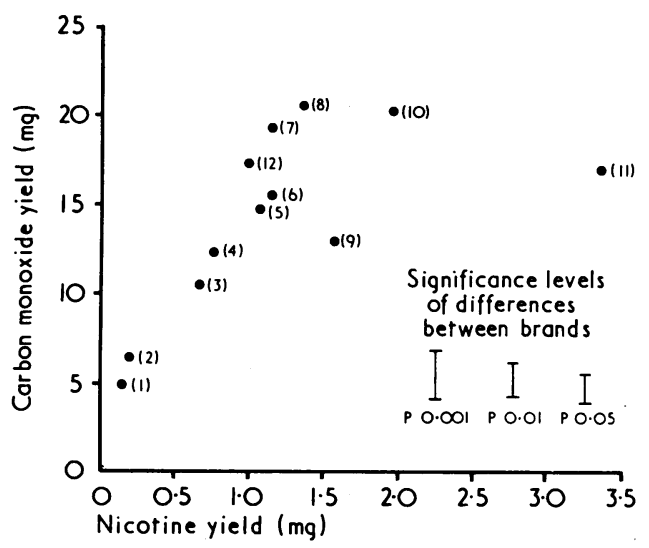

FIG. 1-Carbon monoxide yield ( $\mathrm{mg} /$ cigarette) and nicotine yield of 12 brands of cigarette $(r=0.66 ; P<0.05)$. Significance levels of differences between brands are based on brand (11) with largest variance for the 15 cigarettes measured.
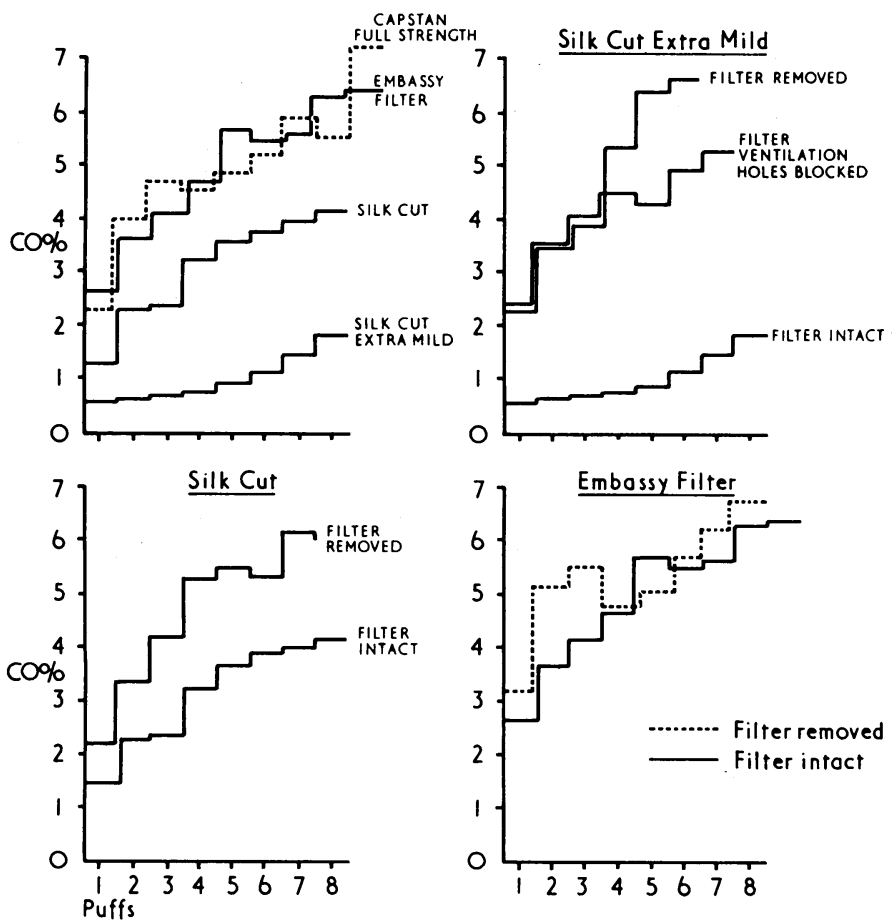

FIG. 2-"Puff-by-puff" profiles of typical brands of cigarette illustrating how CO concentration increases as cigarette is smoked. It is also shown how low CO yields of low nicotine cigarettes (Silk Cut and Silk Cut Extra Mild) are due to filter and its ventilation holes, whereas non-ventilated filters of medium and high nicotine brands (for example, Embassy Filter) have no effect on $\mathrm{CO}$ yield. To maintain standard butt length fewer puffs were taken when filters were removed.
The sample size chosen for each brand was 15 cigarettes; increasing the sample size did not appreciably decrease the standard deviation of the mean $\mathrm{CO}$ concentration of several brands. Some cigarettes were also smoked in a similar manner but with separate analysis of the $\mathrm{CO}$ concentration of each puff (see fig. 2). In addition, the $\mathrm{CO}$ yield of a popular brand of small cigar was determined. The procedure for this was basically similar, though it was necessary to improve the filtering system.

\section{Results}

Details of the brands of cigarette analysed together with their $\mathrm{CO}$ yields are shown in the table. The $\mathrm{CO}$ yields varied by as much as a factor of four. In contrast to the high correlation between tar and nicotine yields $(r=0.96 ; P<0.001)$ the correlation between $\mathrm{CO}$ yield and nicotine yield was low in terms of both average $\mathrm{CO}$ concentration in vol. $\%(r=0.61 ; P<0.05)$ and $\mathrm{CO}$ yield in $\mathrm{mg} /$ cigarette $(\mathrm{r}=0.66$; $\mathbf{P}<0.05$; fig. 1). Examples of the puff-by-puff profiles are given in fig. 2.

\section{Discussion}

Our results show that the $\mathrm{CO}$ yields of British cigarettes vary widely. The 11 brands tested yielded from 5.0 to $20.2 \mathrm{mg} C O$ per cigarette. Values for the medium and high nicotine brands (those with nicotine yields greater than about $1.0 \mathrm{mg}$ ) were in line with other reports, ${ }^{5} 61112$ but there are no reports for the more recently developed mild and extra-mild brands of cigarette with low tar and nicotine yileds. These low nicotine brands seem to have lower than average $\mathrm{CO}$ yields and there appears to be a correlation between nicotine yield and $\mathrm{CO}$ yield (fig. 1). With the medium and high nicotine brands no such relationship is evident.

The puff-by-puff profiles (fig. 2) show that the CO concentration increases as smoking proceeds. This has been reported ${ }^{513}$ and illustrates how smokers risk absorbing progressively more $\mathrm{CO}$ the further down a cigarette they smoke. It is probably explained by the decrease, as the cigarette shortens, of dilution of mainstream smoke by air drawn in through the surrounding porous paper. The puff-by-puff profiles also show that the low $\mathrm{CO}$ yields of the low nicotine brands are due to the filter and its ventilation holes. A higher draw resistance and the position of the ventilation holes in relation to the points of resistance in the filter may be contributing factors. In the medium and high nicotine brands the $\mathrm{CO}$ yield appeared to be unaffected by the filter, which could account for the similar $\mathrm{CO}$ yields of these brands irrespective of whether they were filter-tipped or plain. Earlier reports showed no difference in $\mathrm{CO}$ yield between tipped and untipped cigarettes, ${ }^{56}$ possibly because the filters of the cigarettes examined were of the older, unventilated type. This may have implications for epidemiological studies which compare the risks from smoking plain and filter-tipped cigarettes. Since the older-type filters do not reduce the CO yield it is unlikely 
that $\mathrm{CO}$ could be implicated in any of the health improvements attributable to smoking cigarettes with unventilated filter-tips.

Unfortunately, hopes that tobacco subsitutes may be safer to smoke have not as yet been supported, at least so far as CO production is concerned. Planet cigarettes, which were hastily withdrawn just over a year ago, had a $\mathrm{CO}$ yield well above the other brands used in this study. It was also higher than has ever been reported for cigarettes. Cigarette $\mathrm{X}$, which contains a mixture of tobacco $(70 \%)$ and tobacco-substitute $(30 \%)$, gave a $\mathrm{CO}$ yield which was about average for the group of medium and high nicotine brands. The very high $\mathrm{CO}$ yield of the cigar tested agrees with previous work ${ }^{6}$ and also with the evidence that cigarette smokers who switch to smoking cigars often have high $\mathrm{COHb}$ levels. ${ }^{14} 15$

Our smoking machine "smoked" with a square-waved rather than bell-shaped puff, ${ }^{16}$ and the mean duration of each puff was 1.82 instead of $2.0 \mathrm{~s}$. This is unlikely to have affected the absolute values more than negligibly, and would not affect the comparisons between brands. Our aim was to draw attention to the considerable differences between brands rather than to construct a CO yield table. Since CO may be implicated in some of the adverse consequences of smoking ${ }^{17}$ any assessment of the degree of hazard of a particular brand of cigarette seems to be incomplete without knowledge of the $\mathrm{CO}$ yield. It is only since the public have been given the information, and can consequently act on it, that the tar and nicotine yields have been dramatically lowered by the manufacturers. Official publication of $\mathrm{CO}$ yields might have a similar effect.

We thank Clare Wilson and Upendra Patel for their help, Jean
Crutch for secretarial work, and the Medical Research Council, the Department of Health and Social Security, and the Joint Research Board of St. Bartholomew's Hospital for financial support.

\section{References}

${ }^{1}$ Department of Health and Social Security, Report of the Standing Scientific Liaison Committee to the Secretary of State for Social Services on the Publication of Tar and Nicotine Yields of Packeted Cigarettes. D.H.S.S., London, 1973.

2 "Public Health," Lancet, 1973, 1, 874.

${ }^{3}$ Armstrong, H. E., British Medical fournal, 1922, 1, 992.

${ }^{4}$ Baumberger, J. P., Fournal of Pharmacology and Experimental Therapeutics, 1923, 21, 23.

${ }^{5}$ Mumpower, R. C., Lewis, J. S., and Touey, G. P., Tobacco Science, $1962,6,142$.

${ }^{6}$ Hoffman, D., and Wynder, E. L., Science, 1972, 178, 1197.

' Russell, M. A. H., et al., Lancet, 1973, 2, 687.

${ }^{8}$ Russell, M. A. H., et al., British Medical fournal, 1973, 4, 512.

${ }^{9}$ Hawkins, L. H., Fournal of Scientific Technology, 1967, 13, 21.

10 Rothwell, K., and Grant, C. A. (editors), in Standard Methods for the Analysis of Tobacco Smoke, research paper No. 11. London, Tobacco Research Council, 1974.

11 Wynder, E. L., and Hoffman, D., in Tobacco and Tobacco Smoke, p. 442. New York, Academic Press, 1967.

${ }^{12}$ Morie, G. P., Tobacco Science, 1973, 17, 125.

${ }^{13}$ Keith, C. H., in The Chemistry of Tobacco and Tobacco Smoke, ed. I. Schmeltz, p. 149. New York, Plenum Press, 1972.

14 Castleden, C. M., and Cole, P. V., Lancet, 1973, 2, 21.

${ }^{15}$ Cowie, J., Sillett, R. W., and Ball, K. P., Lancet, 1973, 1, 1033.

${ }^{16}$ International Organization for Standardization, "Tobacco and Tobacco Products; Routine Analytical Cigarette-Smoking Machine; Specification." Draft International Standard ISO/DIS 3308, 1974.

${ }^{17}$ Astrup, P., and Kjeldsen, K., Medical Clinics of North America, 1973, $58,323$.

\title{
Prophylactic Fluoride Treatment and Aged Bones
}

\author{
J. INKOVAARA, \\ R. HEIKINHEIMO, \\ K. JARVINEN, \\ U. KASURINEN, \\ H. HANHIJARVI, \\ E. IISALO
}

British Medical fournal, 1975, 3, 73-74

\section{Summary}

In a double-blind trial with monofluorophosphate $(25 \mathrm{mg}$ fluoride per day) given to 460 aged persons (237 treated, 233 control) for eight months no difference was observed in height, admission to hospital, or mortality. Fractures and exacerbation of arthrosis were more frequent in the fluoride group. Vertebral $x$-ray films showed no difference. The free ionized fluoride levels in the plasma of the fluoride-treated group were still twice as high two months after treatment ended. Fluoride treatment in the prophylaxis of osteoporosis is not recommended unless there is simultaneous measurement of plasma ionized fluoride levels.

\footnotetext{
Institute of Clinical Sciences, University of Tampere, Teiskontie 35, SF-33520 Tampere 52, Finland

J. INKOVAARA, M.D., Associate Teacher of Clinical Sciences

Tampere City Hospital, Koljontie 3, SF-33500 Tampere 50, Finland R. HEIKINHEIMO, M.D., Chief of Geriatric Department

K. JARVINEN, M.D., Physician

K. JARVINEN, M.D., Physician
U. KASURINEN, M.D., Radiologist

Department of Pharmacology, University of Turku, SF-20520, Turku 52, Finland

H. HANHIJARVI, D.D.S., Lecturer in Dental Pharmacology

E. IISALO, M.D., Associate Professor of Pharmacology
}

\section{Introduction}

Fluoride has been used to treat metabolic disturbances and malignant diseases of bone ever since Möller and Gudjonson ${ }^{1}$ first showed its possible application. It may also considerably alleviate pain in osteoporosis. ${ }^{2} 3$

Some population surveys have shown that osteoporosis is less frequent in areas with a high water fluorine content. ${ }^{4}$ In contrast, Korns ${ }^{6}$ noted no such difference. Prophylactic fluoride treatment for osteoporosis has not been tried and this study aimed to investigate whether fluoride prophylaxis slows down the development of osteoporosis in the aged.

\section{Methods and Results}

Two groups were chosen among patients over 65 in the Koukkuniemi municipal home for the aged (Tampere, Finland) according to whether the year of birth was an odd or even number, and in double-blind tests these groups were given respectively one capsule of sodiummonofluorophosphate, corresponding to $25 \mathrm{mg}$ fluorine per day (caps. Fluoryl, Leiras, Turku, Finland) or one capsule of $30 \mathrm{mg}$ sodium bicarbonate as a placebo. The capsules were distinguished only by colour and their contents were known to the manufacturer alone. The series started on 1 June 1971. The fluoride group comprised 237 patients ( 41 men), aged $65-95$, average age $78 \cdot 4$. The controls numbered 223 (58 men), aged 65-94, average age 78.4. Patients with high serum creatinine levels were omitted from the experiment. Patients with known osteoporosis were included and their former treatment continued. A random sample was also taken from each group, comprising 10 normally mobile, 10 poorer, and 10 moving only with assistance, and $x$-ray films of the thoracic and lumbar spine were taken at the start of treatment and after six months. As spontaneous bone 